\title{
Téoros
}

Revue de recherche en tourisme

\section{Culture vécue et représentation touristique}

\section{Marc Laplante}

Volume 7, numéro 1, mars 1988

Cultures régionales et tourisme

URI : https://id.erudit.org/iderudit/1080429ar

DOI : https://doi.org/10.7202/1080429ar

Aller au sommaire du numéro

Éditeur(s)

Université du Québec à Montréal

ISSN

0712-8657 (imprimé)

1923-2705 (numérique)

Découvrir la revue

Citer cet article

Laplante, M. (1988). Culture vécue et représentation touristique. Téoros, 7(1), 25-27. https://doi.org/10.7202/1080429ar d'utilisation que vous pouvez consulter en ligne.

https://apropos.erudit.org/fr/usagers/politique-dutilisation/ 


\section{Culture vécue et représentation touristique}

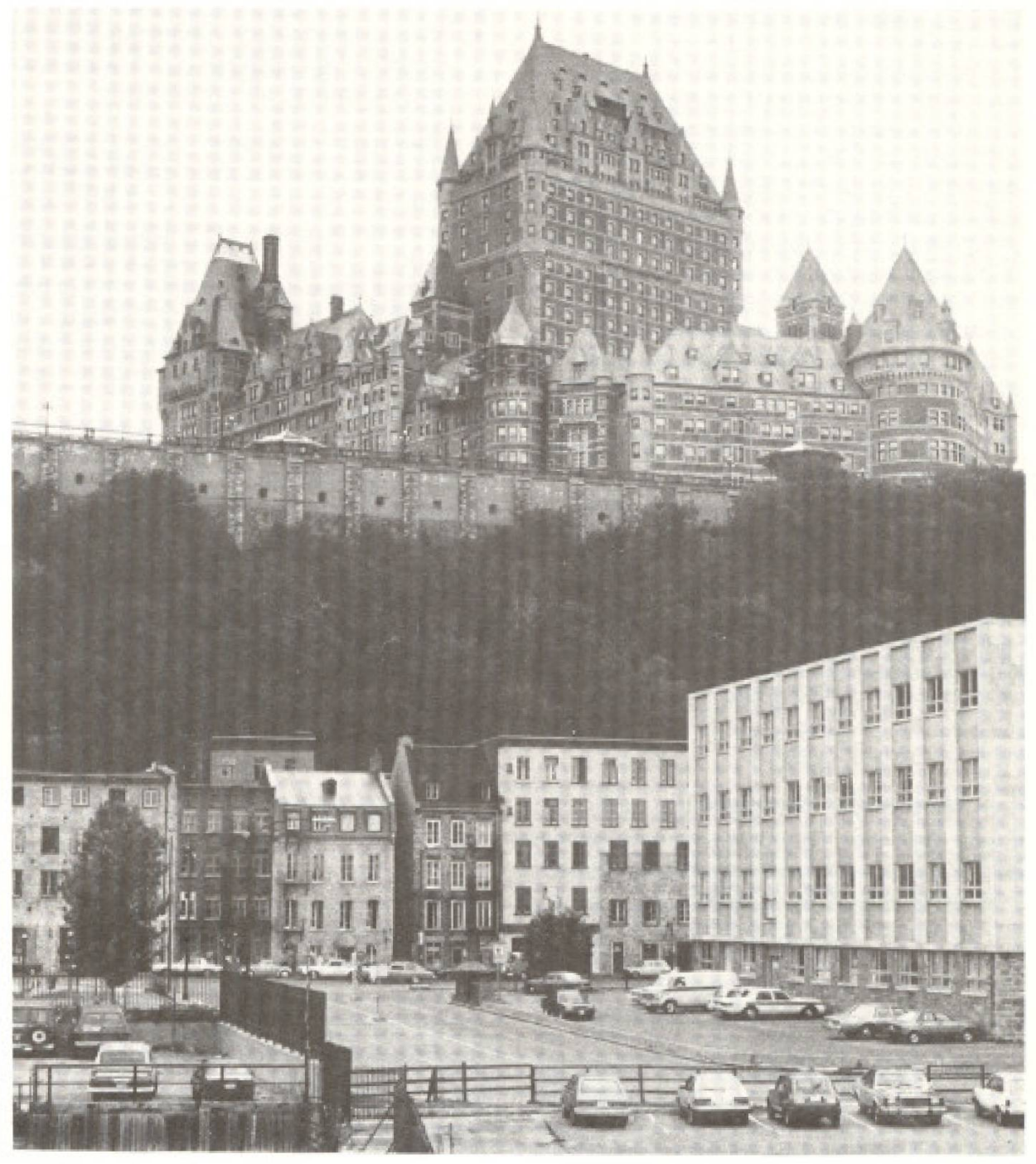

"M. Laplante, sociologue, ast professeur au Departement d'études urtwaines et touristiques de l'Université du Québeè å Móntréal.
Il faudrait bien, dans l'esprit de ce colloque, que je centre ma réflexion sur les rapports qui existent entre tourisme et culture. Permettez-moi toutefois de vous parler avant tout du touriste. Plusieurs des collègues ici présents ne manqueront pas d'examiner le sort de la culture face au développement du tourisme.

Je commencerai par une narration - comme si je voulais vous raconter des histoires - une narratjon tirée de notes d'observation systématique faites dans le Vieux-Québec au cours des étés 1984 et 1986 . Avec une équipe légère d'assistants, j'ai fait ce terrain à partir d'une seule hypothèse large: le tourisme est une expérience culturelle spécifique parce qu'il est une expérience de communication, parce que l'essentiel de cette expérience appartient à l'univers symbolique. En ce sens, il n'est pas exagéré de dire que le tourisme est un mode de connaissance.

Soyez assuré qu'une telle hypothèse n'est pas facile à accepter comme point de départ d'un programme de recherche quand on a parcouru la littérature concernant les significations du tourisme dans les sociétés post-industrielles. Parce que pratiqué sur une vaste échelle par les populations des sociétếs industrialisées, le tourisme a été épinglé, une fois pour toutes, comme phénomène de culture de masse avec tous les opprobres qu'une telle étiquette entraîne: facilité, sensationalisme, "kétainerie", etc. On lui 
oppose une activité plus noble: le voyage, celui des littérateurs, des philosophes, de l'honnete homme qui parcourait le monde en quêtte de savoir et de sagesse. Nous filons vers l'avenir l'oeil dans le rétroviseur disait, je crois, Valery: je voulais essayer de voir autrement car cette interprétation me dérangeait profondément. En 1985, trois cents millions de personnes ont franchi leur frontière nationale à des fins touristiques alors que le tourisme intérieur est deux fois plus grand. Ce peut-il, me disais-je, que les sociétés industrialisées comptassent autant d'ignorants, de sous-doués culturellement?

J'ail done entrepris d'observer des touristes, avec rigueur, sans trop d'idées préconçues, en m"entourant de d"autres observateurs entraînés, en n'hésitant pas à payer de ma personne pour suivre à la trace - des jours entiers - mes sujets, pour compter, cartographier, chonométrer et même fixer sur vidéo leur comportement. En bon sociologue, j'ai pris soin de varier mes sujets d'observation selon les groupes, les types de voyages, etc. Le terrain s'est volontairement limitế à une des formes de tourisme les plus banales et les plus pratiquées, la visite de ville, le "sight-seeing", pratiquée individuellement ou en groupes.

L'objet de cette visite, le Vieux-Quebec, reconnu en 1986 comme Patrimoine Mondial, présenté partout et toujours comme un haut lieu historique et culturel de l'Amérique, est de plus en plus spécifiquement aménagé et animé pour le bien-être et le plaisir des visiteurs. Je me situais donc dans un microscome privilégié pour trouver quelques réponses à mes questions.

\section{Le statut de touriste}

Observer le plus objectivement possible ne dispense pas de bien connaître qui on observe. J'ai inscrit en rouge sur nos fiches de travail quelques traits généraux de ce personnage qui allait performer devant nous; ces individus-touristes etaient d'abord des gens en vacances et, très probablement, en grandes vacances annuelles; des gens done, en train de vivre un temps fort de l'année, un moment exceptionnel sur plusieurs plans: un temps très démarqué par rapport à la vie de tous les jours, un moment de dépenses extraordinaires dans le budget annuel, une période psychologiquement particulière paree que chargée de désirs, d'attentes de choses agréables, excitantes, ennivrantes même, inoubliables autant que possible, etc.; des gens enfin qui étaient des étrangers, par définition, qui expérimentaient de vivre dans des espaces nouveaux et qui faisaient ces expériences sans obligations, done par plaisir.

\section{La visite touristique: un rituel complexe}

Rendre compte ici de toutes les observations déborderait le cadre de cet exposé. Laissezmoi vous en résumer l'essentiel.

- J'ai pu constater d'abord que le touriste passe bien vite sur tout et partout! Par exemple, il "fait" la Place Royale en 15 minutes, en moyenne! Ayant ćtudié à fond cette Place, j'estime qu'il faut au moins $11 / 2$ heures pour en tirer tous les enseignements accessibles aux visiteurs.

- Par contre, j’ai trouvé aussi que ce touriste "serdait"' beaucoup de temps: 30 minutes, en moyenne, sur la rue du Trésor, du temps précieux pour entrer dans toutes les boutiques sans rien acheter le plus souvent, des heures aux terrasses, aux cafés et restaurants, etc.

- Nous avions toujours l'impression que ce touriste n'avançait pas, qu'il déambulait un peu comme un somnambule.

- Chez tous - ou presque - nous avons noté avec quel sérieux, avec quelle application se faisaient ces visites. Leurs comportements - qui pouvaient durer des heures d'affilée - faisaient penser à quelqu'un qui aurait pénétré pour la première fois dans une eglise, avançant sur la pointe des pieds, se demandant s'il pouvait s'aventurer plus avant sans sacrilège..

- Par contre, lors des pauses et des arrêts, le groupe de visiteurs s'animait vivement: couples, familles, noyaux d'amis, petits clans parentaux, regroupement d'inconnus arrivés dans un car, toutes ces cellules sociales s'agitaient périodiquement comme pour se relâcher après un temps de visite vécu de manière révérencieuse.

- Enfin, j'ai pu clairement identifier tout ce qu"il y avait de rituels dans ces comportements de visites: sur un parcours donné, il $\mathrm{y}$ a des endroits précis où on s'arrête pour consulter les cartes ou les livresguides, des endroits précis et des angles précis pour faire une photographie, pour placer les gens à photographier; la déambulation elle-même est rituelle; à preuve: un touriste qui revient à un point de l'espace qu'il a vu 30 minutes plus tôt change de pas et accélère pour le traverser puis reprend sa déambulation typique!

Fixés à nos postes des jours entiers, nous avons observé toutes ces choses - et bien d'autres - chez tous les touristes: chez la grande famille japonaise comme chez le petit couple québécois, dans un "party" d'américains comme dans un groupe d'âge d'or arrivé en minibus, chez l'individu bardé de caméras comme chez celui qui consultait constamment son guide Hachette de 800 pages, chez celui qui s"arrêtait au "Pere du spaghetti" comme chez l"autre qui entrait à "La Ripaille".

Cest dire, en d'autres mots, que nous pouvions retracer, derrière chaque touriste particulier, un type universel, une sorte d'Homo Turisticus analogue à l'homo eoconomicus des sciences économiques. II va sans dire que des différences existent entre les individus quant aux comportements de visite: pour une moyenne observée de 15 minutes à la Place Royale, certains visiteurs ont pris
45 minutes alors que d'autres l'ont traversé en 5 minutes (mais en la visitant tout de mëme de l'extérieur, si on se fie à leur rythme de marche, à leurs gestes typiques, etc.).

\section{La visite touristique: un grand jeu}

La plupart des résultats présentés ci-haut pourraient servir à confirmer les énoncés voulant que l'expérience touristique soit associable à la culture de masse; superficialité, gestes routiniers, recherche des sensations fortes, etc. Pourtant, prise comme un ensemble, cette expérience touristique autorise une autre conclusion, nettement plus prometteuse à mon avis: le cadre général dans lequel l'expérience touristique est vécue reproduit à la lettre celui de toute expérience ludique (selon les analyses de Roger Caillois notamment):

- Elle possede un espace-temps propre. spécifique, tout à fait particulier par rapport à celui de la vie ordinaire.

- Elle est poursuivie pour le seul plaisir qu'elle peut procurer immediatement (quand ce n'est plus amusant, on ne joue plus; quand un touriste s"ennuie quelque part, il fait demi-tour très vite et cherche ailleurs).

- L'expérience touristique se déroule dans le respect d'un ensemble de règles, de rituels qui, pour n'être pas explicites, sont pourtant appliqués de fait par tous.

- Elle est vécue dans un état psychologique général de sur-stimulation. Ce trait, en particulier, ressort bien des observations: cet état est d'abord lié au statut d'étranger; comme tout est nouveau pour lui, les paysages comme les odeurs, les manières de parler comme l'étiquette de la promenade dans les lieux publics, le touriste "travaille" constamment de tous ses sens pour capter, apprendre, décoder, interpréter tout ce qui l'entoure. Ses lenteurs relatives s'expliquent ainsi car il fait sans arrêt du balayage visuel (scanning) comme un radar surveillant un environnement; chacun de ses gestes suppose un apprentissage et une adaptation. Le touriste est done, en visitant, comme en alerte! Cet ćtat est lié aussi à ses désirs et à ses attentes: à chaque tournant de rue, avant chaque entrée dans un lieu donné, le touriste espère être agrétablement surpris, ćtonné. "frappes" par quelque chose; il s"attend à faire des découvertes, à avoir des "révélations" ". Le plaisir recherché tient largement en cela: trouver des choses, des faits, des gens, uniques, exceptionnels, hors de son ordinaire, mềme si ces choses sont cocasses, excentriques, bizarres ou encore, inimaginables, terribles, honteuses... (I'exotisme de la misère!). N'oublions pas qu'on lui a promis cet exotisme, que la promotion touristique se fonde sur lui, que le choix d'une destination de vacanees est largement influencé par cette promotion, etc... 
- Enfin, le jeu comprend toujours des temps forts, des "sommets" , le "clou" de la soirée ou du spectacle, etc.: victoire des jeux de compétition, gains des jeux de hasard, transfert (de type psychanalitique) des jeux d'imitation, quasi-perte de conscience des jeux de vertige, etc. Quand le jeu atteint les formes les plus riches de la vie artistique, au théâtre par exemple, le jeu des acteurs, les jeux scéniques savent "pulser" l'événement de façon telle qu'il procure des temps forts: le rythme des scènes drôles dans une comédie, l'orchestration des instants dramatiques dạn une tragédie, la succession et l'enchaînement des actes, des tableaux et des scènes dans tout spectacle, etc. A la scene, le premier temps fort est le rituel des 3 coups qui annonce la levée de rideau: le monde bascule instantanément dans l'imaginaire. Avec quel art les grands maîtres du spectacle ne savent-ils pas exploiter toute la gamme des émotions pour nous entraîner et nous retenir dans les mondes magiques qu'ils bătissent pour notre plaisir!

Le touriste, tout à son jeu, recherche ces temps forts pour ềtre ému, enlevé, entraîné par l'imaginaire dans des mondes qu'il ne connaît pas. Il souhaite être captivé intensément comme l'enfant qui joue. Tout son voyage, du départ au retour, pourrait être vécu comme un grand jeu si les gens visités prévoyaient mettre-en-scène pour lui la totalité de son séjour. L'heure du départ ne ressemble-t-elle pas, émotionnellement, aux 3 coups précédant la levée du rideau de scene? Les super-attractions ne sont-elles pas souvent les "clous" du voyage?

\section{Laisser vivre au touriste toute son expérience}

L'interprétation du tourisme comme une expérience ludique permet de résoudre plusieurs problèmes de signification mais pose aussi de grandes exigences aux sociétés et aux cultures qui reçoivent:

- Le touriste né me semble plus cet inconscient qui circule dans la culture des autres sans savoir ce qu'il fait. Il est tout à son jeu et ne se laisse pas distraire par les "problèmes" de la société qu'il visite. Apres tout, il n'y vient pas comme journaliste politique, ni comme analyste social, ni comme critique d'art, ni comme anthropologue. Pourquoi alors reprochet-on souvent aux touristes d'ignorer le contexte politique, idéologique, économique, des pays qu'il visite?

- Le touriste n'est pas "fétard" par désir de perturber la tranquilité de ses hötes mais il est "en féte" "par les fortes doses d'émotions et de plaisir qui composent son voyage. Pour qui n'est pas concerné, le spectacle d"un groupe en fête dérange toujours (ah! les voisins du dessus et leur partouze du samedi soir!); on peut souhaiter que les touristes ménagent un peu leurs transports mais on ne peut pas les forcer à prendre des visages d'enterrement.

- Le touriste ne m'apparaît plus comme un ignorant qui refuse de s"instruire; mais le voyage de vacances n'est pas un bane d'école. Il fait des apprentissages à chaque instant de son séjour et il emmagasine une masse de compréhensions de sá propre existence par les comparaisons incessantes qu'il fait avec celle des autres. Les centres d'interprétation de la Place Royale donnent surtout à lire: il nous a fallu 30 minutes pour lire à voix haute tous les textes apparaissant dans le seul centré d'interprétation du commerce en Nouvelle-France à cette Place Royale! $\mathrm{A}$ ce compte-là, il vaudrait mieux inviter les touristes à s'inserire à un cours d"été en histoire.

\section{Tourisme et culture}

- L'expérience touristique ainsi comprise m'apparaitt comme une expérience culturelle au sens premier de ce mot. Entre visiteurs et visités, les interactions peuvent être directes, face à face, entre personnes et elles peuvent être indirectes, c’est-à-dire médiatisées par tous les intermédiaires mis à la disposition des touristes pour favoriser ses relations avec la culture des visités; par exemple, toutes les attractions et leur sacralisation, les guides accompagnateurs, I"animation des places publiques, mais aussi les boutiques, les restaurants, etc. Ces intermediaires sont nombreux et variés et permettent toutes sortes d'échanges: du sight-seeing qui fait voir à la fête organisée qui favorise la participation.

- S'il en est ainsi, il importe de s'attarder sur les correspondances qui devraient exister entre la société qui reçoit les touristes et tout ce qu'elle met en oeuvre pour les accueillir: hospitalité de base (restaurants, hébergement, etc.) mais surtout et c'est ici l'idée nouvelle - les ressources qu"elle "sacralise" (qu'elle rend intéressantes, compréhensibles, ete.), les itinéraires qu'elle propose, les arréts qu'elle aménage (musće, centres d'interprétation, etc.).

- Poussant plus loin, compte tenu de l'interprétation de l'expérience touristique avancée ci-haut, la société qui accueille devrait se mettre-en-scène, "se donner en spectacle". A première vue, ces expressions sembleront pejoratives; mais n'oublions pas, $\mathrm{d}^{+}$une part, qu'une société se donne souvent des spectacles à elle-même: cérémonies religieuses, politiques, fête nationale, grands événements comme les mariages, les enterrements, etc, qu'elle se raconte aussi en spectacle (ex.: Le temps d'une paix); d'autre part, ces mises-en-scène au profit des touristes peuvent devenir de bonnes occasions de création collective, d'exercice d'expressions de soi. Théoriquement, tous les québécois devraient être fondamentalement d'accord avec la version de leur histoire que raconte un des centres d'interprétation de la Place Royale ( 400 ans d'histoire), avec I'histoire militaire de Québec que raconte la maquette animée du Musée du Fort! On est loin du compte dans presque tous les cas parce que le processus qui permettrait à une collectivité de faire ses représentations d'elle-même n'existent pas encore, excepté l'approche écomuséale dans certains cas. Voilà done, à mon avis, un avenir pour les rapports positifs entre tourisme et culture.

- Ces processus, quand ils seront enclenchés, apparaîtront aussi comme des apports certains au développenent des cultures régionales et locales. S'ils respectent I'essentiel de l'expérience touristique recherché par les visiteurs, ils chercheront à se situer dans l'esprit du jeu, univers, très fécond pour l'innovation culturelle; ils rendront compte aussi de ce qu'il y a de plus spécifique, de plus original, unique, marquant dans les cultures qu'ils traduiront en spectacles pour les visiteurs; identité et authenticité, demandées par les touristes, ne peuvent que servir à l'affirmation culturelle des sociétés qui reçoivent! Enfin, chaque culture régionale (ou sous-régionale) sera différente des autres et le visiteur traversera ainsi sans se lasser toute la société qu'il visite.

- Finalement, en poussant encore la prospective, on peut dire que l'avenir du tourisme risque de solliciter de plus en plus le champ culturel des sociétés visitées. Le premier tourisme de masse s'est contenté d'aventures en surface (en suivant les deux dimensions de la géographie: longitude et latitude): contemplation des paysages, observations sur les places publiques, ete. Tant et aussi longtemps que la planète offrait des coins non encore explorés de cette façon, le tourisme pouvait s'étendre. Aujourd'hui, même les espaces les plus difficilement accessibles ont reçu la visite de touristes.

La prochaine aventure, le nouvel exotisme consistera alors à découvrir une troisième dimension en cherchant à pénétrer plus profondément dans les sociétés visitées: non plus seulement visiter un temple mais participer a la cérémonie; non plus seulement voir des danses mais les apprendre, non plus seulement lire sur l'histoire d'une ville mais la voir en sons et lumières, dans un centre d'interprétation, dans un musée animé ou encore dans une super-production comme celle du Pays du Fou en Vendée (1200 figurants, 3 heures de spectacles en pleine nuit, etc.).

Ce nouveau tourisme était à prévoir car l'expérience touristique s'apprend, s'acquiert par la pratique: plus il voyage, plus le touriste devient, à son corps défendant souvent, un sociologue ou un anthropologue amateur. C'est en fait qu'il se comprend lui-même de mieux en mieux à mesure qu'il comprend les autres. $f$ 